\title{
Model Evaluation and Development for Global Luminous Efficacy Models through On-Site Measurement and Optimization Techniques
}

\author{
Cong Thanh Do ${ }^{1}$, Hui Shen ${ }^{2}$, Ying-Chieh Chan ${ }^{1}$, Xiaoyu Liu ${ }^{2}$ \\ ${ }^{1}$ Department of Civil Engineering, National Taiwan University, Taipei, Taiwan \\ ${ }^{2}$ Department of Civil and Architectural Engineering, \\ Texas A\&M University-Kingsville, Texas, USA
}

\begin{abstract}
Illuminance prediction is critical for accurate daylighting simulation which is essential for daylit space designs. However, illuminance data are unavailable for many locations. There are several widely used luminous efficacy models to estimate illuminance from irradiance such as Perez, Littlefair, Muneer, and Chung models. To validate the performance of these models when applied to different locations, we recorded global and diffuse irradiance, global illuminance, and some meteorology parameters in Taipei and Kingsville. Subsequently, we provided luminous efficacy models for these specific locations by using regression and neural network. The results showed that Muneer and Perez models provide good estimation. Water content described in Perez model does not show significant influence in most of the analysis. Additionally, luminous efficacy does not seem to vary due to different locations, at least for temperature and humidity.
\end{abstract}

\section{Introduction}

Most building occupants like daylight and appreciate the changes in the indoor environment brought by the changes of daylight as long as it is not causing discomfort or disability glare (Galasiu and Veitch, 2006). Designing a daylit space is an important part of architectural design. Architects need to determine window glazing properties for various orientations of a room as well as select shading solution to meet occupants' requirements in daylighting and visual comfort. Daylighting simulation can help architects to predict the amount of daylight received by a work plane and the probability of glare. Additionally, along with the development of advanced dynamic shading control methods, illuminance are not only an essential input for design but also a major input for accurate daylighting, lighting, and shading control. Sometimes, we do not have enough sensors to provide an illuminance distribution map; models can facilitate the controllers to predict illuminance of the working area and to check if daylighting is enough for occupants' activities or whether or not artificial lighting should be turned on with different dimming levels.

The weather file with global horizontal illuminance and direct normal illuminance is critical for accurate annual prediction. Some of the weather data did not have illuminance values since most of the weather stations did not have devices for illuminance measurements. Therefore, most of the weather data use irradiance and luminous efficacy models to calculate illuminance. The luminous efficacy is defined as the ratio between the daylight illuminance and the solar irradiance. In other words, the luminous efficacy is the quotient of luminous flux by radiant flux, in lumens per Watt (Littlefair, 1985).

$\mathrm{Li}$ and Lou (2018) summarized ten luminous efficacy models in their paper. From their summary, we can find that most of the luminous efficacy models categorize efficacy as direct, diffuse, and global luminous efficacies and they are mostly calculated based on solar altitude, sky brightness, sky clearness, and precipitable water. In Vartiainen's paper (Vartiainen, 2000), the models developed by (Perez, Webster, et al., 1987), Littlefair (1988), Olseth and Skartveit (1989), T. Muneer and Kinghorn (1997), and Chung (1992) were tested and compared with a constant model using measured data in Helsinki, Finland. The author concluded that the Perez model was the most accurate one and the others had a relative root mean square difference (RMSD) within $2 \%$ of constant model. Because studies showed that the luminous efficacy varies remarkably from region to region (Kong and Kim, 2013), the popular models were formulated with optimized coefficients at different locations (Azad et al., 2018; Chaiwiwatworakul and Chirarattananon, 2013; Cucumo et al., 2010; Kong and Kim, 2013). Azad et al. (2018) developed the models using formulas from Littlefair, Muneer, Ruiz (Ruiz et al., 2001), and Perez and modifying their coefficients to build global and diffuse luminous efficacy models for a humid sub-tropical region based on the experimental data of New Delhi. However, these models do not fit well for the measurements in Taiwan and Kingsville, Texas, USA from our studies.

Therefore, this study intends to validate these efficacy models - new ones and old ones against two locations Taipei, Taiwan and Kingsville, Texas, USA and to verify the hypothesis that the efficacy models are highly depended on locations. We suspect that the low accuracy of some models in several studies might be due to experimental errors caused by setup and devices rather than locations. Irradiance, illuminance, and some required environments data used in this study were measured in Kingsville and Taipei. Furthermore, we also developed several new empirical models for predicting the global horizontal efficacy for these specific locations 
including an example of using black box model - a neural network in predicting illuminance levels.

\section{Luminous efficacy models review}

This part reviewed a few most important luminous efficacy models and the major parameters used in these models. Besides, we discussed some common misunderstanding and confusions appeared in previous studies and websites.

\section{Perez model}

Perez et al. (1990) used measurements in 1985 collected from ten American sites and three European sites to construct their luminous efficacy models. They indicated solar zenith angle, three-hourly surface dew point temperature, sky clearness, and sky brightness are the main parameters affecting the luminous efficacy calculation. The sky clearness described the cloud level of the sky - the more common terms are overcast sky, partly cloudy sky, or the clear sky and the clearness was categorized into eight intervals representing conditions of the sky from overcast to clear. The brightness described the luminance of the sky from dark to bright. Global luminous efficacy was higher in dark overcast skies compared to bright overcast skies; similarly, it was higher in the overcast skies compare to clear skies (Perez, Webster, et al., 1987). The sky brightness $\Delta$ is given by:

$$
\Delta=\frac{I_{d h^{\times m}}}{E T R N}
$$

where $I_{d h}$ is the diffuse horizontal irradiance $\left[\mathrm{W} \mathrm{m} \mathrm{m}^{-2}\right], \mathrm{m}$ is the relative air mass $[\mathrm{m}]$, and ETRN is the normal incidence extraterrestrial radiation $\left[\mathrm{W} \mathrm{m}^{-2}\right]$ (Perez, Seals, et al., 1987). The relative air mass is regularly determined by:

$$
m=\frac{1}{\sin \alpha}
$$

where $\alpha$ is the solar altitude angle [degree]. It can be calculated using Karsten's formula (Kasten, 1993) to reach an accuracy of $99.6 \%$ for zenith angles up to $89^{\circ}$ :

$$
m=\left[\sin \alpha+0.50572(\alpha+6.07995)^{-1.6364}\right]^{-1} .
$$

Equation (3) only applies to standard atmospheric pressure $\mathrm{P}_{0}=1013.25 \mathrm{mbar}$ at sea level (Azad et al., 2018). For other pressure, the air mass should be corrected by:

$$
m^{\prime}=\frac{m \times P}{P_{0}} .
$$

P can be determined by Lunde (1980):

$$
P=P_{0} \times e^{-0.0001184 h}
$$

where $\mathrm{P}$ is the atmospheric pressure [mbar] and $\mathrm{h}$ is the height above the sea level [m]. The atmospheric precipitable water content $\mathrm{W}[\mathrm{cm}]$ is determined by:

$$
W=e^{0.0693 T_{d}-0.0756}
$$

where $\mathrm{T}_{\mathrm{d}}$ is the surface dew point temperature $\left[{ }^{\circ} \mathrm{C}\right]$ (Perez et al., 1990). The sky clearness noted as $\varepsilon$ is given by:

$$
\varepsilon=\frac{\left(I_{d h}+I_{b n}\right) / I_{d h}+1.041 Z^{3}}{1+1.041 Z^{3}}
$$

where $\mathrm{I}_{\mathrm{bn}}$ is the normal incidence direct irradiance $\left[\mathrm{W} \mathrm{m}^{-2}\right]$, and $\mathrm{Z}$ is the solar zenith angle [radian] (Perez, Seals, et al., 1987). Note that there is one confusion often happened in empirical models - the altitude $\alpha$ in Equation (3) is in degree while the solar zenith angle in Equation (7) is in radian. For each condition of the sky from overcast to clear, four coefficients a, b, c, and d derived from measurements are plugged to calculate global luminous efficacy, direct luminous efficacy, diffuse luminous efficacy, and zenith luminance. The global luminous efficacy $\mathrm{K}_{\mathrm{g}}[\mathrm{lm} / \mathrm{W}]$ can be expressed as:

$$
K_{g}=a_{j}+b_{j} W+c_{j} \cos Z+d_{j} \ln \Delta
$$

where $a_{j}, b_{j}, c_{j}$, and $d_{j}$ are the coefficients categorized by sky clearness $\varepsilon$.

\section{Littlefair model}

Littlefair (1988) recorded the daylight data in Garston, England from 1984 to 1985 to derive the global luminous efficacy in accordance with the solar altitude angle. The global luminous efficacy $\mathrm{K}_{\mathrm{g}}[\mathrm{lm} / \mathrm{W}]$ only relating to the solar altitude angle is determined by:

$$
K_{g}=104.4+0.18 \alpha-0.009 \alpha^{2}
$$

where $\alpha$ is the solar altitude angle [degree].

\section{Chung model}

Chung (1992) measured the luminous efficacy in Hong Kong from 1989 to 1991. Parameters were dependent on the solar altitude and the cloud ratio. Chung proposed the global efficacy model $\mathrm{K}_{\mathrm{g}}[\mathrm{lm} / \mathrm{W}]$ as a function of the cloud ratio and the solar altitude angle. It is determined by:

$$
\begin{aligned}
K_{g}= & D(135.3-25.7 D) \\
& +\left(48.5+1.67 \alpha-0.0098 \alpha^{2}\right)(1-D)
\end{aligned}
$$

where $\mathrm{D}$ is cloud ratio calculated by the ratio of diffuse to global irradiance and $\alpha$ is the solar altitude angle [degree].

\section{Muneer model}

T Muneer and Kinghorn (1998) developed a luminous efficacy model based on measurements from five sites in the United Kingdom in the 1990s. In this model, the luminous efficacy only depended on the clearness index. The global luminous efficacy $\mathrm{K}_{\mathrm{g}}[\mathrm{lm} / \mathrm{W}]$ of Muneer model is determined by:

$$
K_{g}=136.6-74.541 K_{t}+57.3421 K_{t}^{2}
$$

where sky clearness index $\mathrm{K}_{\mathrm{t}}$ is the ratio of horizontal global to extraterrestrial irradiance (T. Muneer and Kinghorn, 1997).

\section{Summary and discussion of the parameters of sky condition}

Solar zenith angle representing the position of the sun is the only parameter included in all luminous efficacy models. The sky clearness and brightness appeared in 
several different studies is usually determined by global irradiance, diffuse irradiance, and position of the sun. However, not all papers use both clearness and brightness and there are some similar wording with different meanings.

Many other parameters are investigated to predict accurately global horizontal illuminance by different authors. Perez et al. (1990) showed water content as a parameter affecting global horizontal illuminance, but most other papers did not include water content in their equations. Table 1 summarizes some parameters used in this paper to estimate luminous efficacies.

Table 1: Summary of some parameters used in models.

\begin{tabular}{|c|c|c|c|c|}
\hline & Perez & Littlefair & Chung & Muneer \\
\hline $\begin{array}{c}\text { Extraterrestrial } \\
\text { radiation normal to } \\
\text { the Sun (ETRN) }\end{array}$ & $\mathrm{X}$ & & & \\
\hline $\begin{array}{c}\text { Extraterrestrial } \\
\text { radiation on a } \\
\text { horizontal surface } \\
\text { (ETR) }\end{array}$ & & $\mathrm{X}$ & \\
\hline Water content & $\mathrm{X}$ & $\mathrm{X}$ & $\mathrm{X}$ & \\
\hline Solar altitude angle & $\mathrm{X}$ & $\mathrm{X}$ & & \\
\hline Air mass & $\mathrm{X}$ & & $\mathrm{X}$ & \\
\hline $\begin{array}{c}\text { Normal incidence } \\
\text { direct irradiance }\end{array}$ & $\mathrm{X}$ & $\mathrm{X}$ & $\mathrm{X}$ & $\mathrm{X}$ \\
\hline $\begin{array}{c}\text { Diffuse horizontal } \\
\text { irradiance }\end{array}$ & $\mathrm{X}$ & & & \\
\hline $\begin{array}{c}\text { Global horizontal } \\
\text { irradiance }\end{array}$ & & & $\mathrm{X}$ & \\
\hline
\end{tabular}

Here are some typical confusions. First, for calculating the sky brightness, Perez explained the extraterrestrial radiation $\mathrm{I}_{0}$ (ETR) in sky brightness equation as extraterrestrial radiation normal to the Sun, but ETR was typically noted as the normal incidence extraterrestrial radiation in nomenclature (ETRN) instead of ETR (Perez et al., 1990; Perez, Seals, et al., 1987). In TMY3 file (Wilcox and Marion, 2008), ETR represents extraterrestrial radiation on a horizontal surface. Several following papers conducted by other authors calculated ETR when they used Perez model instead of ETRN. Secondly, Perez used three-hourly surface dew point temperature to calculate the atmospheric water content in their paper. Most of the following researchers use hourly surface dew point temperature when applying Perez model.

\section{Experimental data in previous researches}

To validate the global luminous efficacy model, we first need to get accurate measurements of global and diffuse horizontal irradiance as well as global horizontal illuminance. Table 2 summarizes some common instruments in previous experimental studies. In most of the previous studies, thermopile pyranometers were used to measure irradiance while silicon or selenium photometers were used to measure illuminance. For measuring diffuse horizontal irradiance and illuminance, they installed shadow-band to block direct component of the sunlight. Nevertheless, shadow-band not only blocked direct component but also part of the diffuse component; therefore the diffuse component was adjusted accordingly (LeBaron et al., 1980). To measure direct normal irradiance and illuminance directly, sun tracker following the movement of the sun and the created shade is a necessity. Note that the other way around was to measure diffuse and total horizontal irradiance and illuminance and derived the direct normal by using calculated sun position. Other parameters calculated in luminous efficacy models such as ambient temperature, relative humidity, and precipitable water can be obtained using mini-datalogger, mercury thermometer, etc.

Table 2: Summary of instruments used in previous research for efficacy studies.

\begin{tabular}{|c|c|}
\hline Authors & $\begin{array}{l}\text { Instruments } \\
\end{array}$ \\
\hline $\begin{array}{l}\text { Perez, } \\
\text { Webster, } \\
\text { et al. } \\
\text { (1987) }\end{array}$ & $\begin{array}{l}\text { Eppley PSP }\left(\mathrm{I}_{\mathrm{gh}}\right) \text {, Eppley NIP }\left(\mathrm{I}_{\mathrm{bh}}\right) \text {, Eppley PSP } \\
\text { and shadow band (Idh), silicon-based photometer } \\
\left(\mathrm{E}_{\mathrm{gh}}\right) \text {, silicon-based photometer and shading disk } \\
\left(\mathrm{E}_{\mathrm{dh}}\right) \text {, and silicon-based photometer and } 5^{\circ} \text { FOV } \\
\text { Ges. Tube (Ebh). }\end{array}$ \\
\hline $\begin{array}{l}\text { Wright et } \\
\text { al. (1989) }\end{array}$ & $\begin{array}{l}\text { Eppley PSP }\left(\mathrm{I}_{\mathrm{gh}}\right) \text {, Eppley NIP }\left(\mathrm{I}_{\mathrm{bh}}\right) \text {, and Li-Cor } \\
\text { photometer and baffled tube }\left(\mathrm{E}_{\mathrm{bh}}\right) \text {. }\end{array}$ \\
\hline $\begin{array}{l}\text { Chung } \\
(1992)\end{array}$ & $\begin{array}{l}\text { Kipp \& Zonen thermoelectric pyranometer }\left(\mathrm{I}_{\mathrm{gh}}\right) \text {, } \\
\text { Kipp \& Zonen thermoelectric pyranometer } \\
\text { incorporated with a shadow ring }\left(\mathrm{I}_{\mathrm{dh}}\right) \text {, cosine and } \\
\text { color-corrected Si-photo-element sensor ( }\left(\mathrm{E}_{\mathrm{gh}}\right) \text {, } \\
\text { and cosine and color-corrected Si-photo-element } \\
\text { sensor incorporated with a shadow ring }\left(\mathrm{E}_{\mathrm{dh}}\right) \text {. }\end{array}$ \\
\hline $\begin{array}{l}\text { Vartiainen } \\
(2000)\end{array}$ & $\begin{array}{l}\text { Kipp \& Zonen CM } 11 \text { pyranometer }\left(I_{\text {gh }}\right), \text { Kipp \& } \\
\text { Zonen CM } 121 \text { shadow ring }\left(\mathrm{I}_{\mathrm{dh}}\right) \text { and } \\
\text { Krochmann FET30-C15-0U-D8 photometer } \\
\left(\mathrm{E}_{\mathrm{gh}}\right) .\end{array}$ \\
\hline $\begin{array}{l}\text { Cucumo } \\
\text { et al. } \\
(2010)\end{array}$ & $\begin{array}{l}\text { Kipp \& Zonen CM } 11 \text { pyranometer }\left(\mathrm{I}_{\mathrm{gh}}\right) \text {, Kipp \& } \\
\left.\text { Zonen CH-1 NIP pyrheliometer ( } \mathrm{I}_{\mathrm{bn}}\right) \text {, FET-GV } \\
\text { photometer }\left(\mathrm{E}_{\mathrm{gh}}\right) \text {, FET L03 0U DX photometer } \\
\left.\text { ( } \mathrm{E}_{\mathrm{bn}}\right) \text {, and Kipp \& Zonen 2AP solar tracker (solar } \\
\text { tracker). }\end{array}$ \\
\hline $\begin{array}{l}\text { Kong and } \\
\text { Kim } \\
(2013)\end{array}$ & $\begin{array}{l}\left.\text { MS-802 pyranometer ( } \mathrm{I}_{\mathrm{gh}} \text { and } \mathrm{I}_{\mathrm{dh}}\right) \text {, Kipp \& Zonen } \\
\left.\text { CHP1 pyrheliometer ( } \mathrm{I}_{\mathrm{bn}}\right) \text {, ML-020S-0 luxmeter } \\
\left(\mathrm{E}_{\mathrm{gh}} \text { and } \mathrm{E}_{\mathrm{dh}}\right), \text { ML-010SD (E } \text { (E), MS-300LR (sky } \\
\text { scanner), and STR-21 sun tracker (sun tracker). }\end{array}$ \\
\hline $\begin{array}{l}\text { Azad et } \\
\text { al. (2018) }\end{array}$ & $\begin{array}{l}\left.\text { Eppley pyranometer ( } \mathrm{I}_{\mathrm{gh}} \text { and } \mathrm{I}_{\mathrm{dh}}\right), \mathrm{Li} \text { 210-SA } \\
\left.\text { photometer ( } \mathrm{E}_{\mathrm{gh}} \text { and } \mathrm{E}_{\mathrm{dh}}\right) \text {, and Testo mini- } \\
\text { datalogger (ambient temperature and relative } \\
\text { humidity). }\end{array}$ \\
\hline $\begin{array}{l}\text { Fabian et } \\
\text { al. }(2018)\end{array}$ & $\begin{array}{l}\text { Kipp \& Zonen CM } 3 \text { radiometer }\left(\mathrm{I}_{\mathrm{gh}}\right) \text {, Kipp \& } \\
\left.\text { Zonen CM } 3 \text { radiometer ( } \mathrm{I}_{\mathrm{dh}}\right) \text {, Si KOSAT } 010 \\
\text { sensor (Egh and Edh), rain gauge Metra } \\
\text { (precipitable water), mercury thermometer } \\
\text { (temperature), and psychrometer by August } \\
\text { (relative humidity). }\end{array}$ \\
\hline
\end{tabular}

Studies found both illuminance and irradiance were difficult to measure to a high degree of accuracy, the primary sources of uncertainties are color correction, cosine correction, levelling, frost, condensation and dirt on sensors, obstructions, calibration, sensor response, temperature effects, shade ring corrections, and vertical efficacy measurements (Littlefair, 1985). According to Tregenza et al. (1994), measurements involving very low solar altitudes (less than $5^{\circ}$ ) and very low irradiance 
values (less than $50 \mathrm{~W} \mathrm{~m}^{-2}$ ) should be removed to reduce the uncertainty in the calculation.

\section{Methodology}

\section{Experimental data}

We recorded the irradiance and illuminance in Taipei and Kingsville using the same sets of sensors and instruments for both locations. Direct luminous efficacy can be calculated by using global luminous efficacy minus diffuse luminous efficacy. Because we did not measure diffuse horizontal illuminance, only global luminous efficacy is considered in this paper.

Figure 1 shows the illuminance sensor measuring global horizontal illuminance, and pyranometer measuring global horizontal solar irradiance supplied by LI-COR Inc. Another instrument (shown in Figure 2) supplied by Delta-T Devices is employed to measure the diffuse component of irradiance. It prevents direct radiation using a perforated hemispherical dome instead of a shadow ring.

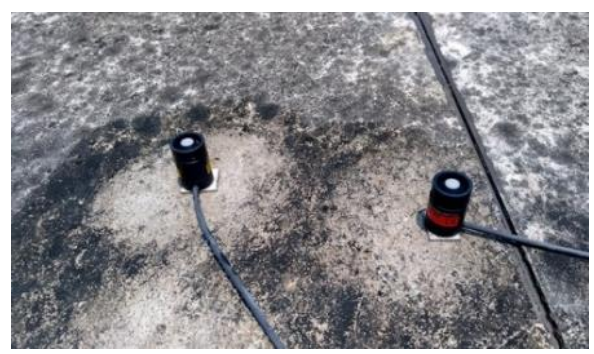

Figure 1: LI-210R sensor (left) and LI-200R sensor (right).

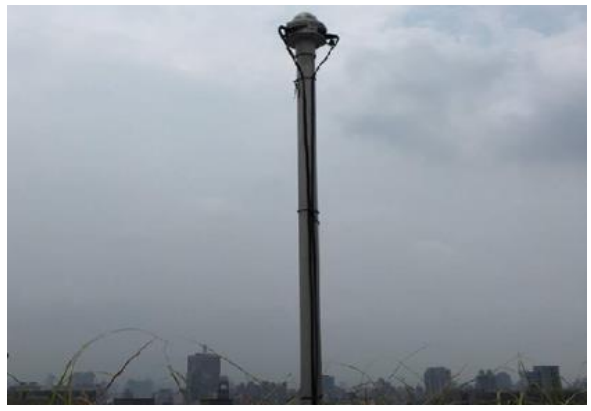

Figure 2: SPNI sunshine pyranometer.

The sensors were placed on the roof of Civil Engineering Research building at National Taiwan University for the measurements in Taipei and on the roof of Engineering building on campus of Texas A\&M University Kingsville for the measurements in Kingsville. All the sensors were connected to the DAQ system with at least 22-bit resolution for $\pm 10 \mathrm{~V}$ range, and we collected the data with 5 minutes intervals continuously during JanApril, May-Jun, and Oct-Nov, 2018.

The data with solar altitude less than $5^{\circ}$ or irradiance less than $50 \mathrm{~W} \mathrm{~m}^{-2}$ were removed to reduce uncertainties. The turbulence of the sky condition is another uncertainty hard to deal with. For sensors connected to the same data logger, there is usually a minor time lag for the same set of measurement interval. Sometimes, this 0.1 second time difference will make the sensors sense very different values because the cloud moves very fast.

\section{Model verification and validation}

The models of Perez, Littlefair, Chung, and Muneer were derived from experimental data in the US, France, Switzerland, Hong Kong, and the UK. Predictions are varied by using different models and might be varied for different locations as claimed in previous studies. According to Kottek et al. (2006), the climate in Taipei and Kingsville is humid subtropical climate and they have the similar latitudes, 25.04 and 27.5 respectively. Therefore, we would like to verify the applicability of these models and to investigate which one is the most suitable for calculating daylight availability for Taipei and Kingsville in this study and practical applications. Besides, we would like to check if different locations using the same set of instruments got similar results.

\section{Regression of coefficients}

Since we already know the form of equations of these commonly used efficacy models, to get the best results for these set of measurements we use regression skills to find the optimized coefficients by using least square error method. The newly developed empirical model was again compared to measurement results to determine which model's form is the fittest one based on our measurement and which parameters are not as important as it seems. Also, to check if other researchers' newly developed empirical models work well here, we also compared the results calculated by Azad's coefficients (Azad et al., 2018) which was developed for a hot and humid climate just like these two selected locations against our measurements.

\section{Neural network}

A neural network can fit any numeric input data for numeric target data using sigmoid hidden neurons and linear output neurons. However, deciding on how to set up the network could be a difficult task and avoiding overfitting is another issue. Therefore, we need sufficient and unbiased input as well as output databases $(\mathrm{Li}$ and Lou, 2018). We use four different combinations of inputs. We fine-tuned the number of nodes and layers with cross-validation skills by dividing the set into 10 different training- validation sets. After the network generated, we can predict output data based on input data and update the model while new data was collected.

\section{Results}

Optimized Perez model using least squares method

Table 3: Perez model regression coefficients based on the measurements in Taipei.

\begin{tabular}{|c|c|c|c|c|}
\hline $\boldsymbol{\varepsilon}$ bin & $\mathbf{a}_{\mathbf{i}}$ & $\mathbf{b}_{\mathbf{i}}$ & $\mathbf{c}_{\mathbf{i}}$ & $\mathbf{d}_{\mathbf{i}}$ \\
\hline 1 & 110.681 & 0.623 & 2.694 & -7.196 \\
\hline 2 & 112.242 & 0.846 & -2.119 & -6.595 \\
\hline 3 & 104.503 & 0.151 & 11.187 & -6.440 \\
\hline 4 & 101.748 & 0.027 & 13.259 & -5.568 \\
\hline 5 & 106.919 & 1.182 & -0.880 & -3.814 \\
\hline 6 & 111.750 & 1.694 & -1.733 & -0.063 \\
\hline 7 & 115.183 & 3.031 & 6.735 & 5.864 \\
\hline 8 & 93.316 & 6.520 & 6.153 & -1.042 \\
\hline
\end{tabular}


Table 4: Perez model regression coefficients based on the measurements in Kingsville.

\begin{tabular}{|c|c|c|c|c|}
\hline $\boldsymbol{\varepsilon}$ bin & $\mathbf{a}_{\mathbf{j}}$ & $\mathbf{b}_{\mathbf{j}}$ & $\mathbf{c}_{\mathbf{j}}$ & $\mathbf{d}_{\mathbf{j}}$ \\
\hline 1 & 106.342 & 1.056 & 2.156 & -6.125 \\
\hline 2 & 101.448 & 2.077 & 1.887 & -7.973 \\
\hline 3 & 96.160 & 1.207 & 5.157 & -12.669 \\
\hline 4 & 91.781 & 1.168 & 8.937 & -12.321 \\
\hline 5 & 92.187 & 0.774 & 10.355 & -9.035 \\
\hline 6 & 96.080 & 1.513 & 4.611 & -5.187 \\
\hline 7 & 93.329 & 1.921 & 5.100 & -5.052 \\
\hline 8 & 104.084 & 1.753 & 2.240 & -0.874 \\
\hline
\end{tabular}

The coefficients of global luminous efficacy for different sky clearness $\varepsilon$ categories regressed based on the measurements in Taipei and Kingsville are shown in Table 3 and Table 4 .

\section{Optimized Littlefair model using least squares method}

The global luminous efficacy $\mathrm{K}_{\mathrm{g}}[\mathrm{lm} / \mathrm{W}]$ is determined by:

$$
\text { For Taipei: } K_{g}=114.376+0.195 \alpha-0.003 \alpha^{2}
$$

$$
\text { For Kingsville: } K_{g}=108.145+0.165 \alpha-0.001 \alpha^{2}
$$

where $\alpha$ is the solar altitude angle [degree].

\section{Optimized Chung model using least squares method}

The global luminous efficacy $\mathrm{K}_{\mathrm{g}}[\mathrm{lm} / \mathrm{W}]$ is determined by:

For Taipei:

$$
\begin{aligned}
K_{g}= & D(107.038+17.628 D) \\
& +\left(112.636+0.211 \alpha-0.003 \alpha^{2}\right)(1-D)
\end{aligned}
$$

For Kingsville:

$$
\begin{aligned}
K_{g}= & D(115.176+4.264 D) \\
& +\left(102.622+0.334 \alpha-0.003 \alpha^{2}\right)(1-D)
\end{aligned}
$$

where the $\mathrm{D}$ is the ratio of diffuse to global irradiance and $\alpha$ is the solar altitude angle [degree].

Optimized Muneer model using least squares method The global luminous efficacy $\mathrm{K}_{\mathrm{g}}[\mathrm{lm} / \mathrm{W}]$ is determined by:

$$
\text { For Taipei: } K_{g}=137.130-55.918 K_{t}+34.857 K_{t}^{2}
$$

For Kingsville:

$$
K_{g}=129.499-39.834 K_{t}+22.105 K_{t}^{2}
$$

where sky clearness index $\mathrm{K}_{\mathrm{t}}$ is the ratio of horizontal global to extraterrestrial irradiance.

\section{Model accuracy}

In model comparison, we use root mean square error (RMSE) which is a common and simple function to calculate the distance between estimates and observations and is widely used for model comparison. RMSE gives relative high weight to higher errors. As shown in Table 5 and Table 6, Muneer model is the most accurate model for both Kingsville and Taipei and the second one is Perez model when using coefficients described in original paper. Littlefair model has the lowest accuracy. While both Perez and Muneer models achieve good results, Muneer model requires fewer parameters than Perez model that makes it easier to apply if the luminance efficacy is the only concern. However, Perez model includes further applications such as estimating illuminance on tilt surface that might be useful in some cases. The Azad's coefficients model reveals higher errors compared to the original models in both Kingsville and Taipei. Azad's Littlefair model shows negative results for predicting global horizontal illuminance if the solar altitude is equal or greater than $7^{\circ}$, we suspect it is due to confusion of radians and degrees. Therefore, we ignore the global horizontal illuminance of Azad's Littlefair model. The results show that the climate type might not be the sole reason why different locations have very different results.

Table 5: RMSE [lux] of predicted global horizontal illuminance in Kingsville using different luminous efficacy models.

\begin{tabular}{|c|c|c|c|c|}
\hline RMSE [lux] & $\begin{array}{c}\text { Perez } \\
\text { model }\end{array}$ & $\begin{array}{c}\text { Littlefair } \\
\text { model }\end{array}$ & $\begin{array}{c}\text { Chung } \\
\text { model }\end{array}$ & $\begin{array}{c}\text { Muneer } \\
\text { model }\end{array}$ \\
\hline $\begin{array}{c}\text { Original } \\
\text { coefficients }\end{array}$ & 1168 & 4753 & 2662 & 986 \\
\hline $\begin{array}{c}\text { Azad's } \\
\text { coefficients }\end{array}$ & 1715 & - & - & 2011 \\
\hline $\begin{array}{c}\text { Coefficients } \\
\text { developed } \\
\text { from } \\
\text { measurements } \\
\text { in Taipei }\end{array}$ & 1436 & 1575 & 1214 & 1141 \\
\hline $\begin{array}{c}\text { Coefficients } \\
\text { developed } \\
\text { from }\end{array}$ & 570 & 964 & 814 & 791 \\
$\begin{array}{c}\text { measurements } \\
\text { in Kingsville }\end{array}$ & & & & \\
\hline
\end{tabular}

Table 6: RMSE [lux] of predicted global horizontal illuminance in Taipei using different luminous efficacy models.

\begin{tabular}{|c|c|c|c|c|}
\hline RMSE [lux] & $\begin{array}{c}\text { Perez } \\
\text { model }\end{array}$ & $\begin{array}{c}\text { Littlefair } \\
\text { model }\end{array}$ & $\begin{array}{c}\text { Chung } \\
\text { model }\end{array}$ & $\begin{array}{c}\text { Muneer } \\
\text { model }\end{array}$ \\
\hline $\begin{array}{c}\text { Original } \\
\text { coefficients }\end{array}$ & 1521 & 4136 & 2139 & 874 \\
\hline $\begin{array}{c}\text { Azad's } \\
\text { coefficients }\end{array}$ & 1928 & - & - & 2165 \\
\hline $\begin{array}{c}\text { Coefficients } \\
\text { developed } \\
\text { from } \\
\text { measurements } \\
\text { in Taipei }\end{array}$ & 586 & 937 & 687 & 610 \\
\hline $\begin{array}{c}\text { Coefficients } \\
\text { developed } \\
\text { from } \\
\text { measurements } \\
\text { in Kingsville }\end{array}$ & 877 & 1247 & 931 & 856 \\
\hline
\end{tabular}

Table 5 and Table 6 reveal that models accuracy can be improved by using coefficients regressed from on-site measurements. The RMSE values also reduce when we use Kingsville meteorological parameters on Taipei and vice versa except regressed Perez model and regressed Muneer model using Taipei data on Kingsville. 
However, the RMSE reduction is minimal meaning the models with original coefficients are already good enough. In the model with newly regressed coefficients, Perez model's RMSE is smaller than Muneer's. However, the difference is not significant enough to conclude whether or not water content is indeed an important parameter.

Among further analysis, the Littlefair model applying original coefficients underestimates the global horizontal illuminance. The errors increase following the Sun's altitude as shown in Figure 3. We might be able to improve the model's accuracy by improving the coefficients related to solar altitude.
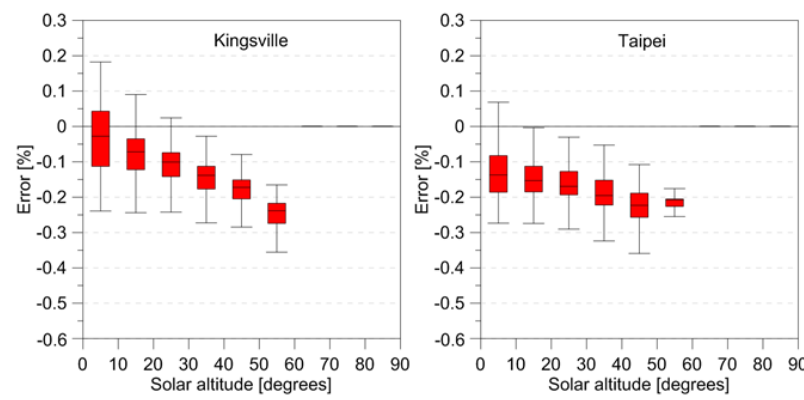

Figure 3: Predicted global horizontal illuminance errors using Littlefair model against solar altitude angle.

As shown in Figure 4, Perez model constantly underestimates global horizontal illuminance. On the other hand, from Figure 5, we can find Muneer model sometimes overestimates the results and sometimes underestimates the results. We can also find that the overall trends of Kingsville and Taipei are similar. The hypothesis that some errors might be caused by the instruments or measurements set up is possible while it cannot be fully concluded.

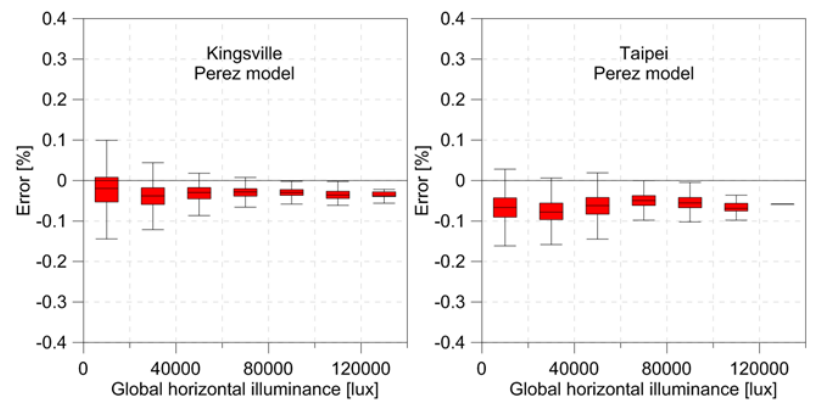

Figure 4: Predicted global horizontal illuminance errors using Perez model in Kingsville and Taipei.
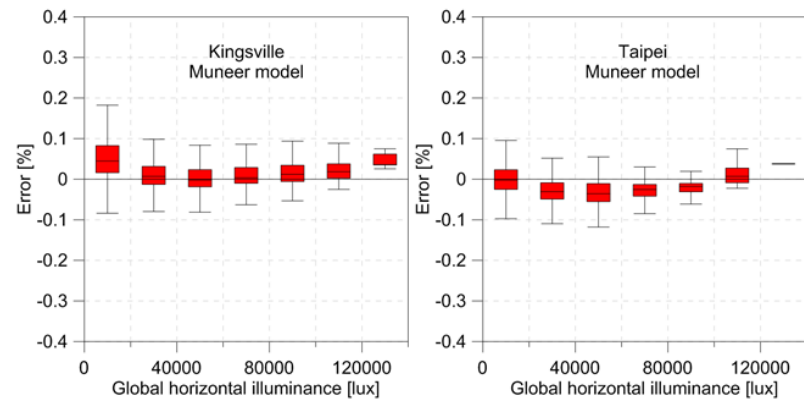

Figure 5: Predicted global horizontal illuminance errors using Muneer model in Kingsville and Taipei.
As described in the methodology session, we use four different combinations of inputs derived from four models we evaluated to build the neural network model. The neural network model achieved better results than the other models. While not significant, the Perez model's parameters achieved the best results as shown in Table 7 and Table 8. However, with only two parameters - global solar radiation and solar altitude angle, we can already achieve a very good result. Nonetheless, the neural network model requires enough amount of inputs data set to build and to verify. For the design stage, this method is not practical. Conversely, for control strategy, it provides the ability to tune the model based on new measurements on site.

Table 7: RMSE [lux] of predicted global horizontal illuminance in Kingsville using a neural network with different parameters.

\begin{tabular}{|c|c|}
\hline Parameters & RMSE [lux] \\
\hline $\begin{array}{c}\text { [Perez] Global solar radiation, water content, } \\
\text { solar zenith angle, and sky brightness }\end{array}$ & 523 \\
\hline $\begin{array}{c}\text { [Littlefair] Global solar radiation and solar } \\
\text { altitude angle }\end{array}$ & 707 \\
\hline $\begin{array}{c}\text { [Chung] Global solar radiation, solar altitude } \\
\text { angle, and cloud ratio }\end{array}$ & 673 \\
\hline $\begin{array}{c}\text { [Muneer] Global solar radiation and sky } \\
\text { clearness index }\end{array}$ & 704 \\
\hline
\end{tabular}

Table 8: RMSE [lux] of predicted global horizontal illuminance in Taipei using neural network with different parameters.

\begin{tabular}{|c|c|}
\hline Parameters & RMSE [lux] \\
\hline $\begin{array}{c}\text { [Perez] Global solar radiation, water content, } \\
\text { solar zenith angle, and sky brightness }\end{array}$ & 485 \\
\hline $\begin{array}{c}\text { [Littlefair] Global solar radiation and solar } \\
\text { altitude angle }\end{array}$ & 568 \\
\hline $\begin{array}{c}\text { [Chung] Global solar radiation, solar altitude } \\
\text { angle, and cloud ratio }\end{array}$ & 566 \\
\hline $\begin{array}{c}\text { [Muneer] Global solar radiation and sky } \\
\text { clearness index }\end{array}$ & 576 \\
\hline
\end{tabular}

Global horizontal illuminance
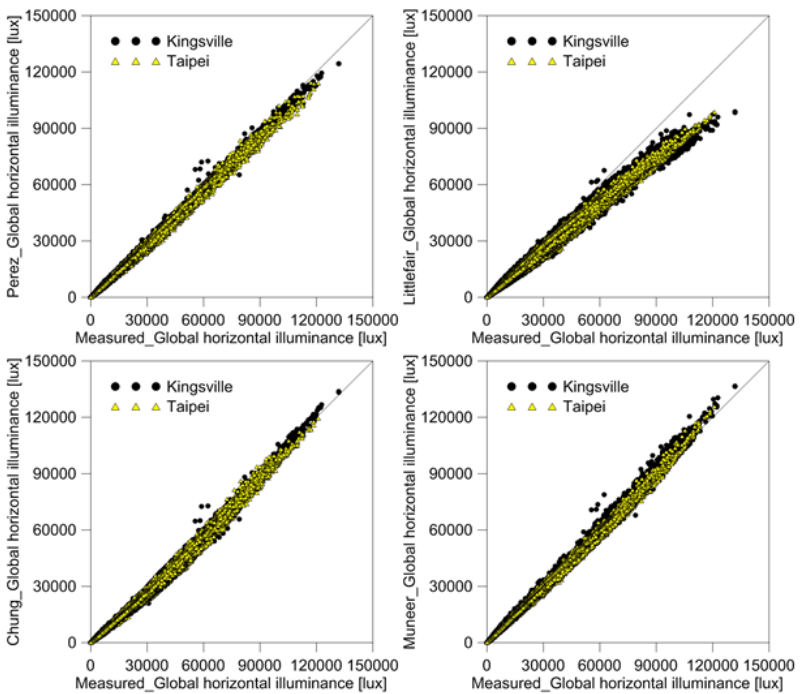

Figure 6: Predicted global horizontal illuminance using four original models in Kingsville and Taipei. 
Figure 6 shows Perez model and Littlefair model underestimate in predicting global horizontal illuminance in Kingsville and Taipei. In contrast, Muneer model has a trend of overestimation when global horizontal illuminance increases. Chung model underestimates for low daylight intensity and overestimates for high daylight intensity.

In Figure 7, the predicted global horizontal illuminance using machine learning fit the measured global horizontal illuminance although the accuracy reduces for high daylight intensity in Taipei.
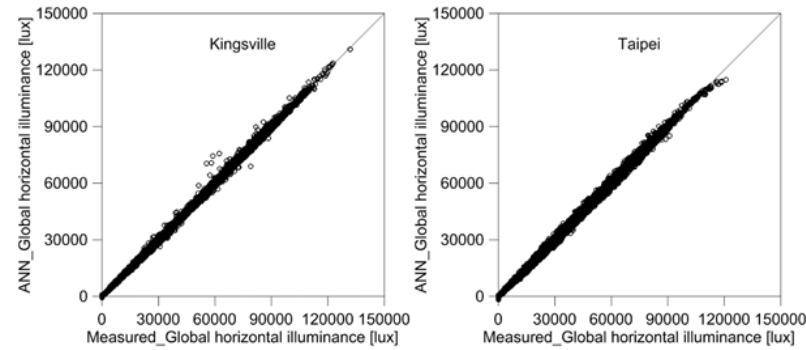

Figure 7: Predicted global horizontal illuminance using machine learning with global solar radiation, water content, solar zenith angle, and sky brightness in Kingsville and Taipei.

\section{Conclusions}

The verification using experimental data of Taipei, and Kingsville shows that Muneer model achieves lowest RMSE and the second lowest one is the Perez model. The atmospheric precipitable water content described in the Perez model does not show significant influence in most of the analysis although, in the neural network model and models with new coefficients, the combinations include water content did achieve lowest RMSE. However, the difference is small.

Littlefair model significantly underestimates the overall illuminance. While previous studies claimed that a different location would have different daylight efficacy model, the results did not fully support this hypothesis. At least, the difference seems not due to temperature and humidity. Because when compared to another model developed for a hot and humid climate, the results are not better than the original one. On the other hand, the results from two different locations using the same sets of measurement devices showed a similar trend. Nevertheless, more locations and data are needed to verify the hypothesis.

This study also showed that even when local illuminance measurement data is not available, the original Perez and the Muneer models should be able to provide good enough estimation. Although the neural network provides lowest RMSE, it is hard to share the optimized luminous efficacy models for the users. However, it might be useful when applied to advanced dynamic shading, and lighting control.

\section{Acknowledgement}

The work described in this paper was substantially supported by a grant from the Ministry of Science and
Technology, Taiwan (project no. MOST 108-2636-E002-005).

\section{References}

Azad, A. S., et al. (2018). Model development and evaluation of global and diffuse luminous efficacy for humid sub-tropical region. Renewable Energy, 119, 375-387.

Chaiwiwatworakul, P., \& Chirarattananon, S. (2013). Luminous efficacies of global and diffuse horizontal irradiances in a tropical region. Renewable Energy, $53,148-158$.

Chung, T. (1992). A study of luminous efficacy of daylight in Hong Kong. Energy and Buildings, 19(1), 45-50.

Cucumo, M., et al. (2010). Correlations of direct solar luminous efficacy for all sky, clear sky and intermediate sky conditions and comparisons with experimental data of five localities. Renewable Energy, 35(10), 2143-2156.

Fabian, M., et al. (2018). Monthly luminous efficacy models and illuminance prediction using ground measured and satellite data. Solar Energy, 162, 95108.

Galasiu, A. D., \& Veitch, J. A. (2006). Occupant preferences and satisfaction with the luminous environment and control systems in daylit offices: a literature review. Energy and Buildings, 38(7), 728742.

doi:https://doi.org/10.1016/j.enbuild.2006.03.0x 1

Kasten, F. (1993). Discussion on the relative optical air mass. International Journal of Lighting Research and Technology, 25(3), 129-130.

Kong, H. J., \& Kim, J. T. (2013). Modeling luminous efficacy of daylight for Yongin, South Korea. Energy and Buildings, 62, 550-558.

Kottek, M., et al. (2006). World map of the KöppenGeiger climate classification updated. Meteorologische Zeitschrift, 15(3), 259-263.

LeBaron, B. A., et al. (1980). Corrections for diffuse irradiance measured with shadowbands. Solar Energy, 25(1), 1-13.

Li, D. H., \& Lou, S. (2018). Review of solar irradiance and daylight illuminance modeling and sky classification. Renewable Energy, 126, 445-453.

Littlefair, P. J. (1985). The luminous efficacy of daylight: a review. Lighting Research \& Technology, 17(4), 162-182.

Littlefair, P. J. (1988). Measurements of the luminous efficacy of daylight. Lighting Research \& Technology, 20(4), 177-188.

Lunde, P. J. (1980). Solar thermal engineering: space heating and hot water systems. New York, John Wiley and Sons, Inc., 1980. 635 p. 
Muneer, T., \& Kinghorn, D. (1997). Luminous efficacy of solar irradiance: Improved models. International Journal of Lighting Research and Technology, 29(4), 185-191. doi:10.1177/14771535970290040401

Muneer, T., \& Kinghorn, D. (1998). Luminous Efficacy Models - Evaluation against UK Data. Journal of the Illuminating Engineering Society, 27(1), 163-170.

Olseth, J. A., \& Skartveit, A. (1989). Observed and modelled hourly luminous efficacies under arbitrary cloudiness. Solar Energy, 42(3), 221-233. doi:https://doi.org/10.1016/0038-092X(89)90014-5

Perez, R., et al. (1990). Modeling daylight availability and irradiance components from direct and global irradiance. Solar Energy, 44(5), 271-289.

Perez, R., et al. (1987). A new simplified version of the Perez diffuse irradiance model for tilted surfaces. Solar Energy, 39(3), 221-231.

Perez, R., et al. (1987). Variations of the luminous efficacy of global and diffuse radiation and zenith luminance with weather conditions - description of a potential method to generate key daylight availability data from existing solar radiation data bases. 38(1), 33-44.

Ruiz, E., et al. (2001). Assessment of Muneer's Luminous Efficacy Models in Madrid and a Proposal for New Models Based on His Approach. Journal of Solar Energy Engineering, 123(3), 220-224. doi:10.1115/1.1385200

Tregenza, P., et al. (1994). Guide to recommended practice of daylight measurement.

Vartiainen, E. (2000). A comparison of luminous efficacy models with illuminance and irradiance measurements. Renewable Energy, 20(3), 265-277.

Wilcox, S., \& Marion, W. (2008). Users manual for TMY3 data sets: National Renewable Energy Laboratory Golden, CO.

Wright, J., et al. (1989). Luminous efficacy of direct irradiance: variations with insolation and moisture conditions. Solar Energy, 42(5), 387-394. 